\title{
BIOTECNOLOGIA: USO DE TÉCNICAS MOLECULARES COMO AUXILIO NO CONTROLE SUSTENTÁVEL DO PERCEVEJO BRONZEADO (THAUMASTOCORIS PEREGRINUS CARPINTEIRO E DELLAPÉ 2006), PRAGA DO EUCALIPTO
}

\section{BIOTECHNOLOGY: USE OF MOLECULAR TECHNIQUES AS AN AID IN THE SUSTAINABLE CONTROL OF THE BRONZEED PERCEPTION (THAUMASTOCORIS PEREGRINUS CARPENTER AND DELLAPÉ 2006), PRAGUE OF THE EUCALYPTUS}

\author{
Tarcisio Tomás Cabral de Sousa ${ }^{1}$; Ariadne Marques ${ }^{2}$; Felipe Gomes Moreira ${ }^{3}$;Any Caroliny \\ Pinto Rodrigues ${ }^{4}$; Marcelo Luiz de Laia ${ }^{5}$
}

DOI: https://doi.org/10.31692/978-65-991061-7-0.143-152

\section{RESUMO}

O Eucalipto tem conquistado grande importância econômica para diversos países. Com grande destaque para os plantios para fins energéticos mediante a produção de carvão vegetal e lenha. É utilizado, ainda, na geração de madeira para serraria e produção de óleos para indústrias farmacêuticas, nesse cenário, o Brasil destaca-se como maior produtor de celulose. Seu grande potencial para usos múltiplos e a grande variedade de subprodutos aproveitáveis do plantio de eucalipto lhe conferem grande importância socioeconômica. Porém alguns fatores bióticos vêm causando grandes injurias nas plantas e consequentemente prejuízos econômicos. Dentre eles, tem-se o inseto praga Thaumastocoris peregrinus que chegou a pouco mais de uma década em nosso país, e tornou-se uma praga com considerável potencial de dano econômico a plantações de eucalipto. Trata-se de um inseto fitófago, que ao sugar a seiva provoca pontos cloróticos nas folhas que podem evoluir para um aspecto bronzeado, o principal sintoma do ataque, e que dá nome ao inseto, percevejo bronzeado. A inviabilidade de utilizar o controle químico devido à falta de produtos registrados e às restrições para a certificação das florestas, aliada a pouca eficácia de outros métodos de controle, como o biológico, tornam necessário investigar novas abordagens que possibilitem o seu controle. Uma das possibilidades para o controle, sem agredir o meio ambiente, é a busca por mecanismos de controle espécie-específico, que pode basear-se em alvos proteicos exclusivos dessa praga. Para isso, a primeira etapa é a extração de DNA do organismo alvo para, depois, identificar genes alvo presentes nesse genoma que sejam essenciais a sobrevivência do inseto. Trabalhos com essa abordagem já se encontram em execução em nossas pesquisas. Com esse objetivo, testaram-se 2 protocolos de extração de DNA em espécimes de percevejo bronzeado. Os resultados obtidos mostraram que apenas um dos protocolos possibilitou a obtenção de DNA com qualidade e quantidade suficientes para o desenvolvimento das próximas etapas.

Palavras-Chave: Biologia Molecular, Inseto-Praga, Eucalipto.

\footnotetext{
1 Doutorando em Ciência Florestal, UFVJM- Uniniversidade Federal dos Vales do Jequitinhonha e Mucuri, tarcisiocox@hotmail.com

2 Doutorando em Ciência Florestal, UFVJM- Uniniversidade Federal dos Vales do Jequitinhonha e Mucuri, ariadne_marqs@hotmail.com

3 Graduando em Engenharia Florestal, UFVJM- Uniniversidade Federal dos Vales do Jequitinhonha e Mucuri, fgom0506@gmail.com

4 Doutorando em Ciência Florestal, UFVJM- Uniniversidade Federal dos Vales do Jequitinhonha e Mucuri, com anycarol_rd@hotmail.com

${ }^{5}$ Doutor, UFVJM- Uniniversidade Federal dos Vales do Jequitinhonha e Mucuri, marcelolaia@gmail.com
} 


\begin{abstract}
Eucalyptus has been gaining great economic importance in many countries, especially in plantations for energy purposes through charcoal and firewood, which is also used in the generation of wood for sawing and production of oils for pharmaceutical industries. production of cellulose being the largest producer, there are innumerable the byproducts of eucalyptus plantation, showing the great socioeconomic importance that this plant has, but some biotic factors have been causing great insults in the plants and consequently economic losses, one of them is $\mathrm{T}$. peregrinus insect plague that has reached a little more than a decade in our country, is a recent pest whose potential economic damage to eucalyptus plantations has been considerable, being a phytophagous insect, when sucking the sap, causes chlorotic points in the leaves that can evolve for a tan appearance, the main symptom of the attack, and which gives its name to the insect. Since chemical control can not be carried out due to the lack of registered products or due to restrictions on the certification of forests and due to other control methods, such as biological control, they are still incipient and ineffective, it is necessary to investigate new approaches that enable its control. One of the possibilities for control and without attacking the environment is the search for mechanisms of speciesspecific control, which may be based on protein targets unique to this pest. To do so, the first step is to extract DNA from the target organism to then study genes present in that genome and discover the target genes that are already running in our research. For this purpose, 2 DNA extraction protocols were tested on bronzed bed bug specimens. The obtained results show that only one of the protocols allowed the obtaining of DNA with quality and in sufficient quantity for the next steps.
\end{abstract}

Keywords: Molecular Biology, Insect-Prague, Eucalyptus..

\title{
INTRODUÇÃO
}

O gênero Eucalyptus pertence à família Myrtacea e é originário da Austrália e ilhas adjacentes. Destaca-se como o gênero mais plantado no mundo em virtude de seu rápido crescimento, produtividade, grande capacidade de adaptação a variadas condições climáticas e por ter inúmeras aplicações em diferentes setores (FONSECA et al., 2010). Atualmente no Brasil, cerca de 5,7 milhões de hectares do território são ocupados por florestas de Eucalipto (IBÁ, 2017).

Os dados atuais mostram que, a matéria prima oriunda das florestas de eucalipto é responsável por suprir as demandas na produção de celulose e papel, óleo essencial, madeira para serraria, movelaria e para energia (carvão, lenha, etc). E tem grande importância para o meio ambiente, já que o seu cultivo auxilia na fixação de carbono, além de ser uma alternativa para recuperação de áreas degradadas.

O setor florestal brasileiro tem destaque mundial pela alta produtividade das florestas plantadas (IBÁ, 2017). Tendo em vista a importância e grande potencial de produtividade da eucaliptocultura perturbações de origem biótica podem causar inúmeras perdas. Essas perturbações podem ser causadas por distúrbios fisiológicos, ataque de pragas e, ou doenças. Acarretando grandes perdas econômicas para o produtor as pragas florestais, em especial, têm 
estagnado ou mesmo reduzido a produtividade dos plantios. A quantidade de pragas e a intensidade com que elas atacam os plantios de eucalipto vêm aumentando cada vez mais, o que tendo sido motivo uma grande de preocupação para os silvicultores.

A aproximadamente uma década a eucaliptocultura vem padecendo com o ataque de uma nova praga o percevejo bronzeado, Thaumastocoris peregrinus Carpintero \& Dellapé 2006 (Hemiptera: Thaumastocoridae). Trata-se de um inseto exótico que foi encotrado no Brasil em 2008 no Rio Grande do Sul e rapidamente se disseminou por quase todo o território brasileiro e passou a provocar danos diretos às plantas, gerando graves prejuízos comerciais (WILCKEN et al., 2010). Até o momento não existe um método de controle eficaz para essa praga e incipientes são os estudos relacionados a mesma.

Estudos estão sendo desenvolvidos por diversos grupos do País e do mundo a fim de identificar algum método de controle no curto prazo, haja vista que produtos químicos são, atualmente, proibidos pelo FSC (Conselho Brasileiro de Manejo Florestal - https://br.fsc.org). E, no longo prazo o plantio de genótipos resistentes ao ataque do inseto deve ser o melhor método de controle. Outro método de controle viável pode ser obtido mediante uso de informações genético-moleculares para identificar genes cujas proteínas são específicas dessa espécie. O que permite sintetizar drogas específicas para essas proteínas de modo a controlar esse inseto. Os estudos genéticos permitem, ainda, o uso da transgenia, que possibilita a clonagem de RNA anti-senso a determinado gene alvo e impedindo a sua expressão. Essas técnicas permitem controlar a praga sem agredir o meio ambiente nem a fauna auxiliar.

Nesse contexto, métodos de análises moleculares constituem uma importante ferramenta para obtenção de dados que auxiliem no controle e monitoramento dessa praga. Além de auxiliar Programas de Melhoramento que visam a obtenção de plantas resistentes.

Micro-organismos normalmente são encontrados em insetos, tanto internos como externamente, podendo manter uma relação harmônica ou desarmônica em relação ao hospedeiro (ALVES, 1998) essa relação tem um papel na regulação do metabolismo, auxilia na digestão, proporcionando o máximo de extração de energia, além de proteger seus hospedeiros do ataque de micro-organismos que possam vir a prejudica-los (YUN et al., 2014).

Os estudos simbióticos vêm obtendo, cada vez mais avanço, especialmente após o desenvolvimento de técnicas moleculares que permitiram o entendimento dessa interação de modo simples, rápido e com baixo custo (PANIZZI; PARRA, 2009).

Conhecer os possíveis micro-organismos que estão associados ao percevejo bronzeado é de extrema importância para aumentar as possibilidades de execução de trabalhos 
moleculares relacionados com o controle não somente dessa praga mais de outras pragas com habito alimentar semelhante. A identificação dos micro-organismos encontrados no aparelho digestório poderá possibilitar o desenvolvimento de estratégias de controle do percevejo bronzeado. Se houver um simbionte imprescindível à sobrevivência do inseto, a ação sobre esse micro-organismo, indiretamente, poderá controlar a praga. Assim, o presente trabalho objetivou testar a eficácia de dois protocolos de extração de DNA, em espécimes percevejo bronzeado a fim de verificar a presença de microrganismos no interior do inseto, mediante posterior amplificação por PCR, com iniciadores específicos.

\section{FUNDAMENTAÇÃO TEÓRICA}

O Brasil vem se destacando no mercado florestal com sua produção de eucalipto equivalente a 5.558.653 ha de área plantada. De toda produção de madeira em nosso país, 91\% são oriundos de floresta plantada (IBÁ, 2017).

Pertence à família Myrtaceae o eucalipto é originário da Oceania e possui cerca de 700 espécies descritas. Atualmente, constituem árvores ou arbustos pertencentes aos gêneros Eucalyptus, Corymbia e Angophora (Wilson et al., 2005; Parra-O. et al., 2009). No Brasil, foi plantado pela primeira vez por Dom Pedro I, em 1825, no Jardim Botânico do Rio de Janeiro (VENTURIN et al., 2014). No entanto sua plantação para fins comerciais foi iniciada por Edmundo Navarro de Andrade no século XX, mais precisamente, no ano de 1904 (MARTINI, 2004; DIAS \& SIMONELLI, 2013).

Os plantios na área florestal são semelhantes a qualquer outra cultura. Sofrem estresse causado por fatores abióticos e bióticos, como pragas e doenças (WANG; VINOCUR; ALTMAN, 2003), que podem comprometer a produção, elevar os custos e gerar grandes perdas financeiras para o setor florestal. Dentre esses, o ataque de novas pragas, como o percevejo bronzeado (Thamaustocoris peregrinus/ Hemiptera: Thaumastocoridae) merece destaque (WILCKEN, 2008). Este inseto começou a ter grande importância econômica em 2002, após infestação de Eucalyptus na cidade de Sydney (NOACK; ROSE, 2007; SOUZA, 2012) e, de lá para cá, vem causando grandes prejuízos econômicos para os produtores de eucaliptos no Brasil e em várias outras partes do mundo.

No Brasil ele foi encontrado pela primeira vez em 2008, em plantações de eucalipto em São Francisco de Assis-RS. Rapidamente esse inseto praga se disseminou pelos principais estados produtores do país. Assim, devido à alta agressividade aliada à facilidade de disseminação, o percevejo bronzeado é considerado uma praga com alto índice de danos econômicos aos plantios de eucalipto, elevando os custos de produção e significativa redução 
na produção. Em alta incidência, ele pode levar a planta à morte (WILCKEN et al., 2010).

Thaumastocoris peregrinus é um inseto de coloração marrom, originário da Austrália, com reprodução sexuada, sendo que cada indivíduo do sexo feminino pode chegar a ovipositar 60 ovos que são de coloração preta, normalmente colocados de forma agrupada nas folhas de eucalipto. Suas ninfas eclodem em seis dias, entre $17-22^{\circ} \mathrm{C}$, passando para a fase adulta após 35 dias e tem um período de longevidade de aproximadamente 20 a 40 dias. São insetos fitófagos succívoros tanto na fase ninfal, quanto adulta, alimentando-se da seiva das plantas (CARPINTERO; DELLAPE, 2006).

A alimentação de percevejos fitófagos succívoros ocorre por meio da introdução do seu aparelho bucal, do tipo sugador, nas folhas e galhos finos, fato que causa danos severos devido a liberação de possíveis enzimas presentes no fluido salivar (PEIFFER; FELTON, 2014). Estas enzimas são produzidas nas glândulas salivares do sistema digestório desses insetos. Portanto, o estudo desse sistema é de suma importância para a busca de possíveis meios de controle da praga.

Os insetos foram os organismos que melhor se desenvolveram e que tiveram melhor sucesso sobre a superfície terrestre. Todo esse processo de rápida adaptação foi ocasionado pela capacidade de se alimentar de uma vasta gama de alimentos (HIROSE, PANIZZI,2009). No entanto, as plantas, que compõem um dos grupos de alimentos dos insetos, também evoluíram e puderam produzir compostos tóxicos aos insetos. Ao contrário dessas, outras espécies de plantas podem produzir compostos cairomônios que atraem os insetos. É por esse motivo que algumas espécies atraem mais insetos que outras.

A fim de obter ajuda para a utilização de dietas oriundas de alimentos que possuam algum tipo de composto adverso ao inseto, estes podem conviver em simbiose com microorganismos, existindo uma relação de associação. A exemplo têm-se bactérias envolvidas na digestão de alimentos mais complexos ou na desintoxicação de compostos vegetais (PANIZZI, PARRA, 2009; CAZEMIER et al., 2003).

A maioria dos insetos está envolvida com alguma forma simbiótica com microorganismos e a maior parte dessas relações está ligada a bactérias, podendo, também, ser com fungos ou protozoários (BRUNE, 2003; RIO et al., 2003).

Atualmente, técnicas de biologia molecular de última geração vêm permitindo a identificação de micro-organismos em diversos sistemas. Essas técnicas baseiam-se na amplificação de sequências altamente conservadas de DNA, estas após o seu sequenciamento, permitem identificar, por meio de comparação em banco de dados genômicos, se existem similaridades entre elas e outras de micro-organismos conhecidos. Isso permite identificar, 
por comparação, quais são os simbiontes que estão interagindo com um dado inseto, por exemplo, (BRAUMAN et al., 2001; WERNEGREEN, 2002).

Estas técnicas consideram a extração, amplificação e análise de sequência de DNA diretamente do inseto. Uma dessas técnicas é a Reação em Cadeia da Polimerase (PCR). A PCR é um método de amplificação, in vitro, de fragmentos específicos de ácidos nucleicos proposta por Kary Mullis, em 1987 (MULLIS; FALOONA, 1987). A PCR permite a amplificação de sequências específicas de ácido desoxirribonucleico (DNA) por meio da ação da enzima Taq DNA polimerase e de oligonucleotídeos iniciadores sobre um DNA molde. Esta técnica é conduzida em um equipamento automatizado e computadorizado, denominado termociclador, o qual alterna as temperaturas por determinados períodos de tempo, possibilitando a ocorrência de ciclos repetitivos de desnaturação e síntese de DNA (KONEMAM, et al., 2001). A característica principal dessa técnica é amplificar exponencialmente cópias do material genético a partir de pouca quantidade dele (MESQUITA et al., 2001).

\section{METODOLOGIA}

O presente estudo foi realizado no Laboratório de Genética e Biotecnologia Florestal, localizados no Departamento de Engenharia Florestal situado na Universidade Federal dos Vales do Jequitinhonha e Mucuri no Campus JK na Cidade de Diamantina, MG.

Espécimes de percevejo bronzeado foram coletados em árvores de eucalipto nas proximidades da Universidade. Após a coleta os insetos foram desinfestados com hipoclorito de sódio a $2 \%$ e lavado duas vezes com água destilada autoclavada. Posteriormente, o DNA total foi extraído seguindo os protocolos 12 descrito por NISHIGUCHI e colaboradores (2002) e o descrito por FALEIRO e colaboradores (2003). A partir da amostra de DNA obtida foi realizada uma PCR utilizando oligonucleotídeos iniciadores específicos para amplificação de material genético de microrganismos (Tabela 1).

\begin{tabular}{c|c|c}
\multicolumn{3}{|c}{ Tabela 1 Oligonucleotídeos utilizados na amplificação } \\
Iniciador & SEQUÊNCIA (5' a 3') & Especificidade \\
\hline $63 \mathrm{f}$ & AGGCCTAACACATGCAAGTC & Eubacteria \\
\hline $1087 \mathrm{r}$ & CTCGTTGCGGGACTTACCCC & Eubacteria \\
\hline FirmF & TACGTGCCAGCAGCCGCGGTAATA & bacteria \\
\hline FirmR & TGCGGGACTTAACCCAACATCTCA & bacteria \\
\hline ITS1f & CTTGGTCATTTAGAGGAAGTAA & All fungi \\
\hline ITS4r & TCCTCCGCTTATTGATATGC & All fungi
\end{tabular}

As reações de amplificação foram realizadas em solução contendo: $5 \mu \mathrm{L}$ de tampão 
para PCR 10X; $2 \mu \mathrm{L} \mathrm{MgCl}_{2} 50 \mathrm{mM} ; 4 \mu \mathrm{L}$ de dNTP $250 \mathrm{mM} ; 0,5 \mu \mathrm{L}$ de Taq DNA polimerase $5 \mathrm{U} / \mu \mathrm{L} ; 1 \mu \mathrm{L}$ de cadainiciador; $2 \mu \mathrm{L}$ de DNA 20ng/ $\mu \mathrm{L}$ e água ultra pura tipo I esterilizada para volume final de $50 \mu \mathrm{L}$.

As reações foram realizadas em um termociclador automático MyCycler (BioRAD). A qualidade e a concentração das amostras de DNA obtidas foram analisadas mediante eletroforese em gel de agarose a 0,8\%, corado com brometo de etila, com posterior visualização sob luz UV, em transiluminador (Loccus Biotecnologia Transluminator L. Pix). ,

\section{RESULTADOS E DISCUSSÃO}

As extrações apresentaram uma boa quantidade e ótima qualidade de DNA apenas seguindo o protocolo 12 descrito por NISHIGUCHI e colaboradores (2002). O uso do protocolo descrito por FALEIRO et al.(2003) não permitiu resultados satisfatórios (Figura 1).

A amplificação por PCR do DNA genômico extraído permitiu a obtenção de fragmentos de DNA (Figura 1) e (Figura 2).

Figura 1. Imagem de gel de agarose à $0,8 \%$ demonstrando: amostra 1 extraído através do método protocolo de Faleiro, 2003 e a 2 utilizando o protocolo 12 de Nishiguchi, et al., 2001. A amostra 3 é o DNA Diluído = padrão da amostra de DNA genômico extraído a partir de espécimes de T. Peregrinus diluída na proporção de 1:2

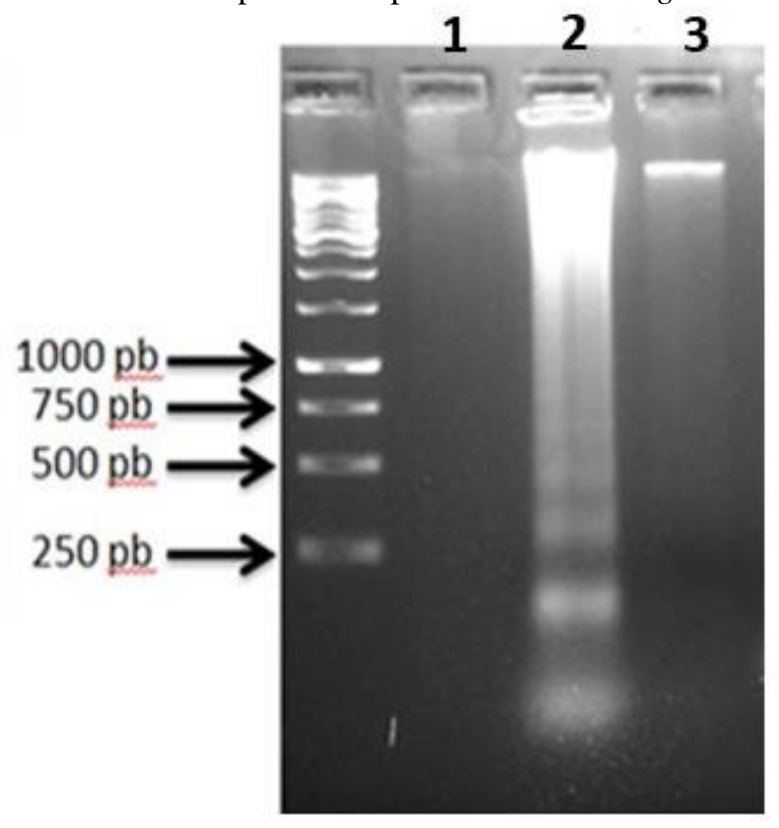


Figura 2. Imagem de gel de agarose à 0,8\% demonstrando: Amostra 1 com DNA de Faleiro e 2 Nishiguchi, amplificação da amostra de DNA diluída com os iniciadores 63f/1087r. Amostra 3 com DNA de Faleiro e 4 Nishiguchi, amplificação da amostra de DNA diluída com os iniciadores Firmef/Firmer. Amostra 5 com DNA de Faleiro e 6 Nishiguchi, amplificação da amostra de DNA diluída com os iniciadores itsf/itsr.

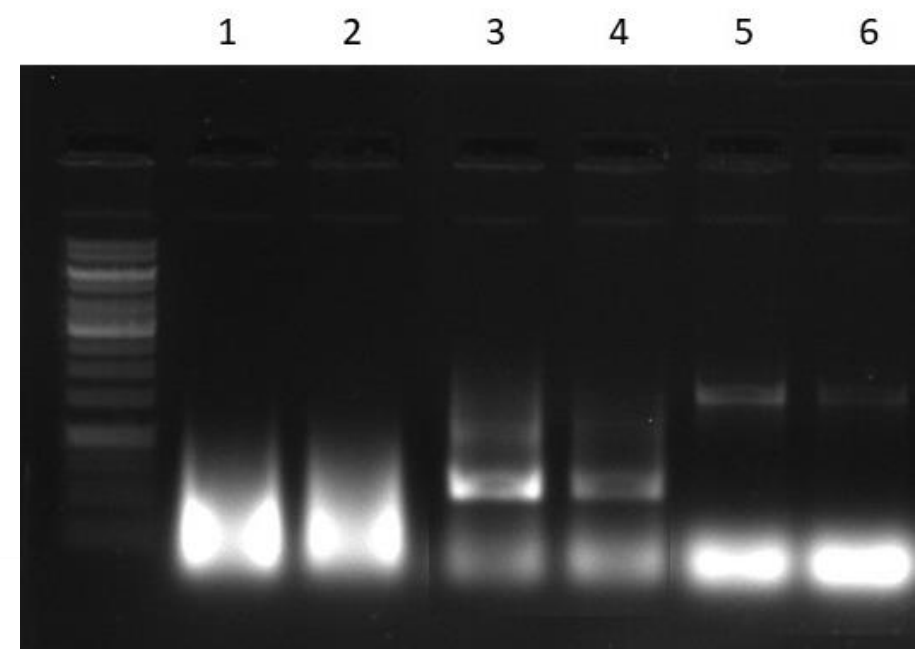

Os resultados apresentados possibilitam inferir que existem bactérias presentes no interior do inseto, podemos afirmar com coerência devido a amostra 3 (Figura 2) que utilizou os iniciadores (firmeF/firmeR) específicos para bactérias amplificaram e que a amostra 5 com iniciadores (its1f/its4r) específicos para fungos. Em um estudo seguinte poder-se-á identificar, verificar se esses micro-organismos são benéficos ou maléficas e quais suas prováveis funções no interior do percevejo bronzeado.

\section{CONCLUSÕES}

Apenas um dos protocolos testados permitiu a adequada extração de DNA genômico dos espécimes de percevejo bronzeado utilizados no estudo. Há bactéria no interior de percevejo bronzeado e estas são passíveis de identificação via técnicas de biologia molecular. Os resultados de similaridade encontrados permitem inferir que se tratam de organismos simbiontes.

\section{REFERÊNCIAS}

ALVES, S. B. Microrganismos associados a insetos. In: ALVES, S.B. (Ed). Controle microbiano de insetos. Piracicaba: Fealq,1998. p. 75-96.

BRAUMAN, A. et al. Molecular phylogenetic proфling of prokaryotic communities in guts of termites with dijerent feeding habits.Fems Microbiology Ecology, n. 35, p.27-36, 2001.

BRUNE A: Symbionts aiding digestion. In Encyclopedia of insects Edited by: Cardé RT, Resh VH. New York: Academic Press; 2003:1102-1107.

CARPINTERO, D. L.; DELlAPÉ, P. M. A new species of Thaumastocoris Kirkaldy from [150] 
Argentina (Heteroptera: Thaumastocoridae: Thaumastocorinae). Zootaxa 1228: 61-68, 2006.

CAZEMIER, A. E. et al. Promicromonospora pachnodae sp. nov., a member of the (hemi)cellulolytic hindgut flora of larvae of the scarab beetle Pachnoda marginata. Antonie van Leeuwenhoek, v. 83, n. 2, p.135-148, mar. 2003.

DIAS, O. A.; SIMONELLI, G.. Qualidade da Madeira para a produção de celulose e papel MADEIRA PARA A PRODUÇÃ̃O DE CELULOSE E PAPEL.Enciclopédia Biosfera: Centro Científico Conhecer, Goiânia, v. 9, n. 17, p.3632, 2013.

FONSECA, S. M., RESENDE, M. D. V., ALFENAS, A. C., GUIMARÃES, L. M., ASSIS, T. F., GRATTAPAGLIA, D. Manual Prático de Melhoramento Genético do Eucalipto. $1^{\circ} \mathrm{Ed}$. Viçosa: UFV, 2010, 200p. ISBN: 978-85-7269-383-7.

HIROSE, E.; PANIZZI, A. R. Os simbiontes e a nutrição dos insetos. In: R. PANIZZI, A.; PARRA, J. R. Bioecologia e nutrição de insetos: Base para o manejo integrado de pragas. Brasilia-DF: Embrapa Informação Tecnológica, 2009. Cap. 6. p. 19-1164.

IBÁ- Indústria Brasileira de Árvore, 2017.

MARTINI, A. J.O plantador de Eucaliptos:A questão da preservação Florestal no Brasil e o Resgate Documental do Legado de Edmundo Navarro de Andrade. 2004. 332 f. Dissertação (Mestrado) - Curso de História Social, Departamento de História da Faculdade de Filosofia, Universidade de São Paulo, São Paulo, 2004.

NOACK, A. E.; ROSE, H.A. Life-history of Thaumastocoris peregrinus and Thaumastocoris sp. In the laboratory with some observations on behaviour. General And Applied Entomology: The Journal of the Entomological Society of New South Wales Inc., v. 36, p.27-34, 2007.

WANG, W., VINOCUR, B., ALTMAN, A. Plant responses to drought, salinity and extreme temperatures: towards genetic engineering for stress tolerance. Planta, v.218, n.1, p.1-14, 2003.

WILCKEN, C. et al. Bronze bug Thaumastocoris peregrinus Carpintero and Dellapé (Hemiptera: Thaumastocoridae) on Eucalyptus in Brazil and its distribution. Journal of Plant Protection Research, v. 50, n. 2, p. 201-205, 2010.

WILCKEN, C.F. Percevejo bronzeado do eucalipto Thaumastocoris peregrinus (Hemiptera: Thaumastocoridae): ameaça às florestas de eucalipto brasileiras. IPEF Programa de proteção florestal - PROTEF/IPEF. Botucatu, SP, Setembro de 2008.

PANIZZI, A. R.; PARRA, J. R.P. (Ed.). Bioecologia e nutrição de insetos: Base para o manejo integrado de pragas. Brasilia-DF: Embrapa Informação Tecnológica, 2009. 1164 p.

Parra-O C. et al. Phylogeny, major clades and infrageneric classification of Corymbia (Myrtaceae), based on nuclear ribosomal DNA and morphology. Australian Systematic Botany, 22, 384-399, 2009.

PEIFFER, M.; FELTON, G. W. Insights into the Saliva of the Brown Marmorated Stink Bug Halyomorpha halys (Hemiptera: Pentatomidae). Plos One, v.9, n.2, p.1-10, 2014. 
RIO, R. V.M. et al. Comparative Genomics of Insect-Symbiotic Bacteria:: Influence of Host Environment on Microbial Genome Compasition. Applied And Environmental Microbiology, v.69, n.11, p.6825-6832, 2003.

WERNEGREEN, J.J. Genome evolution in bacterial endosymbionts of insects. Nature Reviews Genetics, v.3, n.11, p.850-861, 2002.

MESQUITA, R.A et al. Avaliação de três métodos de extração de DNA de material parafinado para amplificação de DNA genômico pela técnica da PCR. Pesquisa Odontológica Brasileira, v.15, p.314-319, 2001.

NISHIGUCHI, Michele K. et al. DNA Isolation Procedures. In: DESALLE, Rob; GIRIBET, Gonzalo; WHEELER, Ward (Ed.). Techniques in Molecular Systematics and Evolution. Springer Basel Ag, 2001. Cap.12, p.272.

FALEIRO, F. G.; FALEIRO, A. S. G.; CORDEIRO, M. C. R.; KARIA, C. T. Operacionalização da extração de DNA de espécies nativas do cerrado visando análises moleculares. In: CONGRESSO BRASILEIRO DE MELHORAMENTO DE PLANTAS, 2., 2003, Porto Seguro. Melhoramento e qualidade de vida: anais. Porto Seguro: SBMP, 2003. 1 CD-ROM.

MULLIS, K. B.; FALOONA, F. A. Specific synthesis of DNA in vitro via a polymerasecatalyzed chain reaction. Methods In Enzymology, p.335-350, 1987.

SOUZA, G. K. Morfologia de ovos, glândulas salivares e sistemas digestivo e reprodutor de Thaumastocoris peregrinus (Hemiptera Thaumastocoridae). 2012. 47 f. Dissertação (Mestrado) - Curso de Entomologia, Universidade Federal de Viçosa, Viçosa-MG, 2012.

WILSON P. et al. Relationships within Myrtaceae sensu lato based on a matK phylogeny. Plant Systematics and Evolution, 251: 3-19, 2005.

YUN, J.H. et al. Insect gut bacterial diversity determined by environmental habitat, diet, Developmental Stage, and Phylogeny of Host. Applied And Environmental Microbiology, v. 80, n. 17, p.5254-5264, 2014.

KONEMAM, E.W. et al. Diagnóstico microbiológico. Texto e Atlas Colorido. 5 ed. Rio de Janeiro: MEDSI, 2001. 1465p. 